\title{
Selective versus nonselective thoracic fusion in Lenke 1C curves: a meta-analysis of baseline characteristics and postoperative outcomes
}

\author{
Anthony J. Boniello, MD, Saqib Hasan, MD, Sun Yang, MD, Cyrus M. Jalai, BA, Nancy Worley, MS, \\ and Peter G. Passias, MD
}

Division of Spinal Surgery, Department of Orthopaedic Surgery, New York University Medical Center Hospital for Joint Diseases, New York University School of Medicine, New York, New York

OBJECT Lenke 1C curves are challenging to manage surgically due to the structural thoracic deformity and nonstructural lumbar curve. Selective thoracic fusion (STF) is considered the standard of care because it preserves motion of the lumbar segment, yet nonselective STF (NSTF) remains prevalent. This study aims to identify baseline patient characteristics that drive treatment and to compare postoperative outcomes for both procedures.

METHODS Studies that compared baseline and postoperative demographic data, health-related quality of life (HRQL) questionnaires, and radiographic parameters of patients with Lenke $1 \mathrm{C}$ curves undergoing STF or NSTF were identified for meta-analysis. The effect measure is expressed as a mean difference (MD) with $95 \% \mathrm{Cl}$. A positive MD signifies a greater STF value, or a mean increase within the group.

RESULTS One prospective and 6 retrospective case-control studies with sample size of 488 patients (344 STF and 144 NSTF) were identified. Baseline age, sex, and HRQLs were equivalent, except for better scores in the STF group for the Scoliosis Appearance Questionnaire (SAQ): Unrelated to Deformity item (3.47 vs 3.88, $p=0.01$ ) and the Spine Research Society questionnaire, Item 22: Pain (4.13 vs $3.92, p=0.04$ ). Radiographic findings were significantly worse in NSTF, as measured by the thoracolumbar/lumbar $(\mathrm{TL} / \mathrm{L}) \mathrm{Cobb}$ angle $\left(\mathrm{MD}:-4.29^{\circ}, p<0.01\right)$ and $\mathrm{TL} / \mathrm{L}$ apical vertebral translation (AVT) (MD: -6.08, $p<0.01$ ). Radiographic findings significantly improved in STF, as measured in the main thoracic (MT) Cobb angle (MD: $-27.78^{\circ}, p<0.01$ ), TL/L Cobb angle (MD: $-16.24^{\circ}, p<0.01$ ), MT:TL/L Cobb ratio (MD: $-0.21, p<0.01$ ), coronal balance (MD: $0.47, p=0.02$ ), and thoracic kyphosis (MD: $7.87^{\circ}, p<0.01$ ); and in NSTF in proximal thoracic (PT) Cobb angle $\left(24^{\circ}\right.$ vs $\left.14.1^{\circ}, p<0.01\right)$, MT Cobb angle $\left(53.5^{\circ}\right.$ vs $\left.20.5^{\circ}, p<0.01\right)$, and TL/L Cobb angle $\left(41.6^{\circ}\right.$ vs $16.6^{\circ}, p<$ 0.01). Postoperative TL/L Cobb angle $\left(23.1^{\circ}\right.$ vs $\left.16.6^{\circ}, p<0.01\right)$ was significantly higher in STF; but PT Cobb angle, MT Cobb angle, and MT:TL/L Cobb ratio are equivalent.

CONCLUSIONS Patients with larger lumbar compensatory curves displaying a larger degree of coronal translation, as measured by the TL/L AVT, are more likely to undergo an NSTF. Contrary to established guidelines, larger MT curve magnitudes and MT:TL/L Cobb angle ratios have not been found to influence the decision to pursue a selective thoracic fusion. Although overall both STF and NSTF groups are found to have effective postoperative coronal balance, the STF group has only modest improvements in the lumbar curve position as determined by a relatively unchanged TL/L AVT. Furthermore, surgeons may prefer NSTF in patients who may have a worse overall perception of their spinal deformity as measured by HRQL measures of pain and desire for appearance change.

http://thejns.org/doi/abs/10.3171/2015.1.SPINE141020

KEY WORDS scoliosis; Lenke $1 \mathrm{C}$ curve; thoracic fusion; outcomes; spine

ABBREVIATIONS AIS = adolescent idiopathic scoliosis; $A V R=$ apical vertebral rotation; $A V T=$ apical vertebral translation; $H R Q L=$ health-related quality of life; $L I V=$ lowest instrumented vertebra; $\mathrm{MD}=$ mean difference; $\mathrm{MT}$ = main thoracic; NSTF = nonselective thoracic fusion; $\mathrm{PT}=$ proximal thoracic; $\mathrm{SAQ}=\mathrm{Scoliosis}$ Appearance Questionnaire; SRS-22, -24, -30 = Scoliosis Research Society (questionnaires); STF = selective thoracic fusion; TL/L = thoracolumbar/lumbar.

SUBMITTED October 12, 2014. ACCEPTED January 19, 2015.

INCLUDE WHEN CITING Published online August 28, 2015; DOI: 10.3171/2015.1.SPINE141020. 
$\mathrm{T}$ HE Lenke Classification System for adolescent idiopathic scoliosis (AIS) was developed in response to several limitations of the King Classification System, including poor interobserver and intraobserver reliability. It is widely used by surgeons as a guide to differentiate between primary and compensatory curves, to determine the extent of fusion needed in various AIS spinal deformities. ${ }^{25}$ The Lenke 1C/King Type II curve, also known as the "false double major" curve, is characterized by a structural thoracic curve with a significant compensatory nonstructural lumbar curve. Surgical correction focuses on stabilization of significant curves to halt curve progression and attain global spinal balance, while sparing motion segments above and below the fusion construct. However, the optimal surgical strategy for Lenke $1 \mathrm{C}$ curves remains controversial.

The concept of selective fusion in spinal deformity surgery was first introduced by Moe in $1958,{ }^{30}$ and refined by King and colleagues in their analysis of patients undergoing selective thoracic fusion (STF) for King Type II curves. ${ }^{21}$ The results of this study show successful STF performed using Harrington instrumentation with spontaneous correction of the lumbar compensatory curve in patients when the lowest instrumented vertebra (LIV) of the thoracic fusion is centered over the sacrum. Despite the initially promising experiences with STF, postoperative spinal imbalance and progression of the unfused lumbar curve is nevertheless reported. . $^{3,20,38,43}$

With the evolution of spinal instrumentation and surgical techniques, STF has been shown to provide successful correction of the thoracic curve with spontaneous correction of the uninstrumented lumbar curve to allow for a well-balanced postoperative spinal column; ;,6,23,32,34,36,40,42 however, the risk for coronal decompensation remains a concern. ${ }^{1,13,14,24,28,29,31,32,43}$ The decision to include the lumbar compensatory curve by performing a nonselective thoracic fusion (NSTF) may provide a "safer" option in the context of preventing revision surgery for coronal decompensation. ${ }^{32}$ However, it must be weighed against the risk of an increased likelihood of back pain and degenerative changes with a more distal fusion into the mid- and lower lumbar spine. ${ }^{7,8}$

Recent interest in determining risk factors for postoperative decompensation after STF has led to research attempting to elucidate criteria for predicting the optimal surgical strategy. Factors such as proper selection of the LIV, 1,3,4,24,29,31,37,41-43 the main thoracic to thoracolumbar/lumbar (MT:TL/L) ratio, ${ }^{25,28,34}$ thoracic "overcorrection," ${ }^{, 6,6,12,13,16,17,19,25,45}$ and surgical approach have been correlated with risk of postoperative decompensation. Despite guidelines for performing STF, NSTF is still commonly performed, with one study showing only $49 \%$ of patients with Lenke 1C curves being treated with an STF. ${ }^{9}$

Given the heterogeneity in the literature with regard to baseline radiographic parameters and health-related quality of life (HRQL) scores between STF and NSTF, the current study used a meta-analysis to elucidate trends to provide a better understanding of treatment patterns for Lenke $1 \mathrm{C}$ curves. The goals of this meta-analysis were to determine the drivers of STF versus NSTF and to assess the impact of demographic data and radiographic parameters on the decision to perform NSTF over STF. Additionally, we sought to provide descriptive radiographic parameters for STF and NSTF and to compare radiographic findings and HRQL scores between both groups postoperatively.

\section{Methods}

Using an electronic and manual literature search of the PubMed database, studies were identified that report on STF and/or NSTF treatment modalities for Lenke 1Ctype curves. Studies were identified for meta-analysis that compared baseline and postoperative demographic data, HRQLs, and radiographic parameters of patients with Lenke $1 \mathrm{C}$ curves undergoing STF or NSTF. The following search query was used for this review study: Lenke 1C. Studies were eliminated based on title, abstract, and manuscript review with regard to inclusion and exclusion criteria (Table 1). If the study included a subset of patients that met inclusion criteria from which data of interest could be extracted, the subset was included. Baseline patient demographic characteristics, such as age and sex, were included for analysis, as well as pre- and postoperative HRQL questionnaire scores, and radiographic parameters.

To establish inconsistency in the study results, a test for heterogeneity was performed. However, all models include fixed-effects modeling. For statistical analysis, Review Manager version 5.2 (Cochrane) was used. We reported the pooled mean difference (MD) comparing STF with NSTF. Variables reported in only one study, and therefore not using meta-statistics, were compared with a Student t-test. These one-study variables are not a part of the meta-analyses currently conducted; however, they do represent important findings that warrant discussion. We have noted that the findings in just one study are not part of the meta-analyses when presented.

In some studies in which standard deviations were not reported, the standard deviation was estimated based on the reported $\mathrm{p}$ value..$^{15}$ Results are presented graphically, as well as the actual estimated MD with $95 \%$ CIs. The effect measures for continuous variables were calculated using the inverse variance test and expressed as the MD between STF and NSTF treatments. Results are displayed graphically, as well as the actual estimated pooled MD with $95 \%$ CIs. An MD of 0 within the $95 \%$ CI indicates no significant difference between the two treatment options. A positive MD signifies a greater STF value, or a mean increase within the group.

\section{Results}

Using an electronic and manual literature search, 7 studies with a total of 488 patients (344 STF, 144 NSTF) are included (Fig. 1, Table 2). Inclusion into the STF group was defined as LIV at or cephalad to L-1, whereas the NSTF included the LIV at or caudal to L-3. A comparison of baseline demographic characteristics between STF and NSTF cohorts is provided only by Demura et al. (Table 3). ${ }^{10}$ Baseline HRQL scores show a significantly lower score on the Scoliosis Appearance Questionnaire (SAQ): Unrelated to Deformity $(\mathrm{p}=0.010)$ and a significantly lower score on the Scoliosis Research Society (SRS) questionnaire, Item 22: Pain in the STF group $(\mathrm{p}=0.038)$. These 
TABLE 1. Inclusion and exclusion criteria for STF and NSTF articles

\begin{tabular}{|c|c|}
\hline Inclusion Criteria & Exclusion Criteria \\
\hline $\begin{array}{l}\text { Articles published after January } \\
2004\end{array}$ & Less than 24 mos follow-up \\
\hline Patients w/ Lenke $1 \mathrm{C}$ curves & $\begin{array}{l}\text { Case report or series w/ less than } 10 \\
\text { patients }\end{array}$ \\
\hline Surgically treated & Published before January 2004 \\
\hline Clinical follow-up >24 mos & Animal studies \\
\hline English language & $\begin{array}{l}\text { Meta-analysis, biomechanical or } \\
\text { kinematic studies, review articles, } \\
\text { or in vitro studies }\end{array}$ \\
\hline $\begin{array}{l}\text { Use of validated health-related } \\
\text { outcome measures }\end{array}$ & $\begin{array}{l}\text { Single-site results as part of a multi- } \\
\text { center trial }\end{array}$ \\
\hline Reporting of complication rates & $\begin{array}{l}\text { Published in languages other than } \\
\text { English }\end{array}$ \\
\hline $\begin{array}{l}\text { Reporting of radiographic } \\
\text { parameters }\end{array}$ & $\begin{array}{l}\text { Study w/ patient overlap from other } \\
\text { qualifying studies }\end{array}$ \\
\hline
\end{tabular}

finding show that there may be a tendency for surgeons to choose NSTF based on increased baseline pain scores and greater patient desire for change in appearance related to the scoliosis. A comparison of baseline characteristics shows that age was similar between STF patients in all 4 papers (Table 4).

A preoperative comparison between STF and NSTF cohorts is shown in Fig. 2. The MT Cobb angle in STF and NSTF cohorts is equivalent (MD: $-1.01^{\circ}\left[-5.59^{\circ}, 3.57^{\circ}\right], p$ $=0.66$ ). The proximal thoracic $(\mathrm{PT})$ Cobb angle in STF and NSTF cohorts is also equivalent (MD: $-0.90^{\circ}\left[-4.37^{\circ}\right.$, $\left.\left.2.57^{\circ}\right], p=0.61\right)$. The TL/L Cobb angle in STF is significantly less than in NSTF (MD: $-4.29^{\circ}\left[-6.15^{\circ},-2.42^{\circ}\right]$, p $<0.01)$. The MT:TL/L ratio of Cobb angles in STF and NSTF cohorts is equivalent (MD: 0.09 [-0.08, 0.26], $\mathrm{p}=$ 0.28 ). The MT apical vertical translation (AVT) in STF is significantly larger than in NSTF (MD: 5.58 [1.42, 9.74], $\mathrm{p}<0.01)$. The TL/L AVT in NSTF is significantly greater than in STF (MD: -6.08 [-9.66, -2.50], p < 0.01).

The lowest most frequently fused vertebra with instrumentation is L-3 (Fig. 3). A comparison between pre- and postoperative radiographic parameters for the STF group is shown in Fig. 4. The MT Cobb angle in STF significantly decreased when compared preoperatively (MD: $\left.-27.78^{\circ}\left[-30.71^{\circ},-24.85^{\circ}\right], \mathrm{p}<0.01\right)$, and the coronal balance (in centimeters) significantly improved in STF (MD: 0.47 [0.07, 0.87], $\mathrm{p}=0.02$ ). The TL/L Cobb angle in STF significantly decreased from preoperative measurements (MD: $\left.-16.24^{\circ}\left[-17.99^{\circ},-14.48^{\circ}\right], \mathrm{p}<0.01\right)$. The MT:TL/L ratio in STF significantly decreased from baseline (MD: $-0.21[-0.29,-0.12], \mathrm{p}<0.01)$. The TL/L AVT did not significantly change (MD: $-0.42[-2.81,1.97], \mathrm{p}=0.36$ ). In the STF approach, the TL/L apical vertebral rotation (AVR) decrease was insignificant compared with preoperative measurements (MD: $-1.45[-3.74,0.85], \mathrm{p}=0.22$ ). The thoracic kyphosis in STF significantly increased from preoperative measurements (MD: $7.87^{\circ}\left[3.36^{\circ}, 12.39^{\circ}\right]$, p $<0.01)$. Lumbar lordosis in STF did not significantly decrease from baseline $\left(\mathrm{MD}:-1.43^{\circ}\left[-5.59^{\circ}, 2.73^{\circ}\right], \mathrm{p}=0.50\right)$.

A comparison between pre- and postoperative radiographic parameters for the NSTF group is provided by Demura et al. only and therefore is not a part of the present meta-analyses. Those authors' original findings are summarized in Table 5. The PT Cobb angle, MT Cobb angle, and TL/L Cobb angle all showed a significant postoperative decrease $(\mathrm{p}<0.01)$. However, the Cobb ratio $(\mathrm{MT}: T L / \mathrm{L})$ is equivalent $(\mathrm{p}=0.21)$. A comparison between postoperative radiographic parameters between NSTF and STF is provided by Demura et al. only and is therefore not a part of the present meta-analyses. Those authors' original findings are summarized in Table 6 . The $\mathrm{TL} / \mathrm{L}$ Cobb angle is significantly less in NSTF postoperatively $(\mathrm{p}<0.01)$. However, the PT Cobb angle $(\mathrm{p}=0.58)$, MT Cobb angle $(p=0.42)$, and Cobb ratio (MT:TL/L; $p=$ $0.29)$ are equivalent between the two groups.

\section{Discussion}

The basic objective of deformity correction for AIS is to maximize 3D correction by recapitulating coronal and sagittal balance while sparing motion segments above and below the fusion construct to optimize spinal flexibility. The concept of STF was born out of the necessity to accomplish these objectives in all curves amenable to

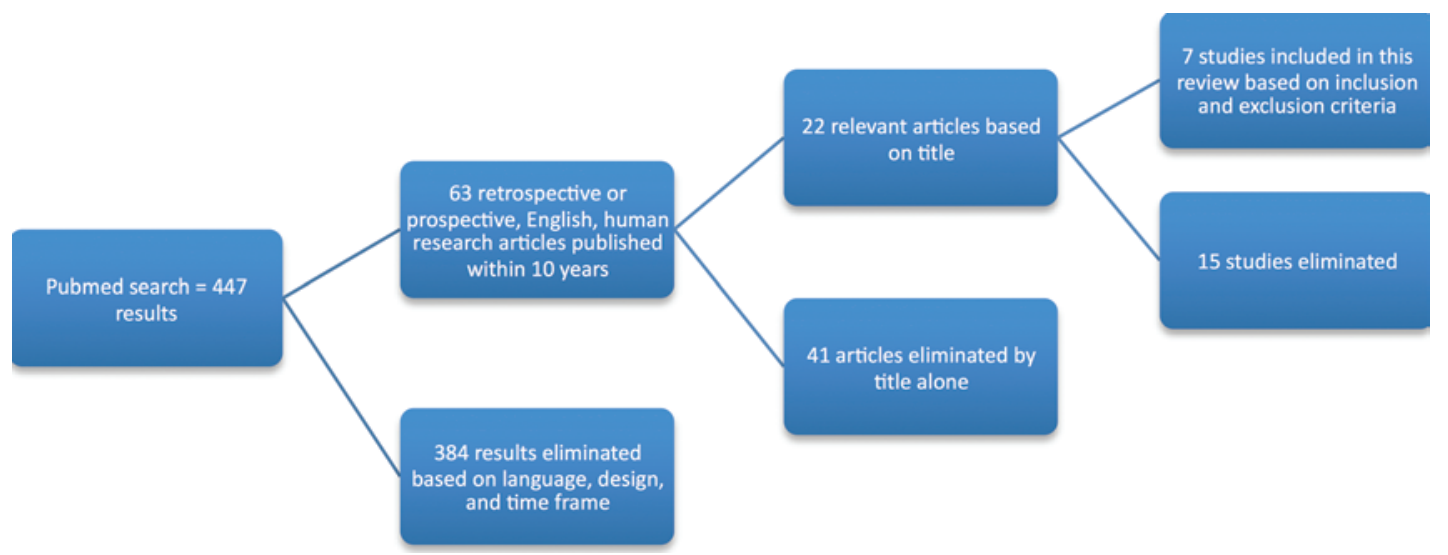

FIG. 1. Flow chart showing study selection process. Studies were eliminated based on title, abstract, and manuscript review based on inclusion and exclusion criteria. Figure is available in color online only. 


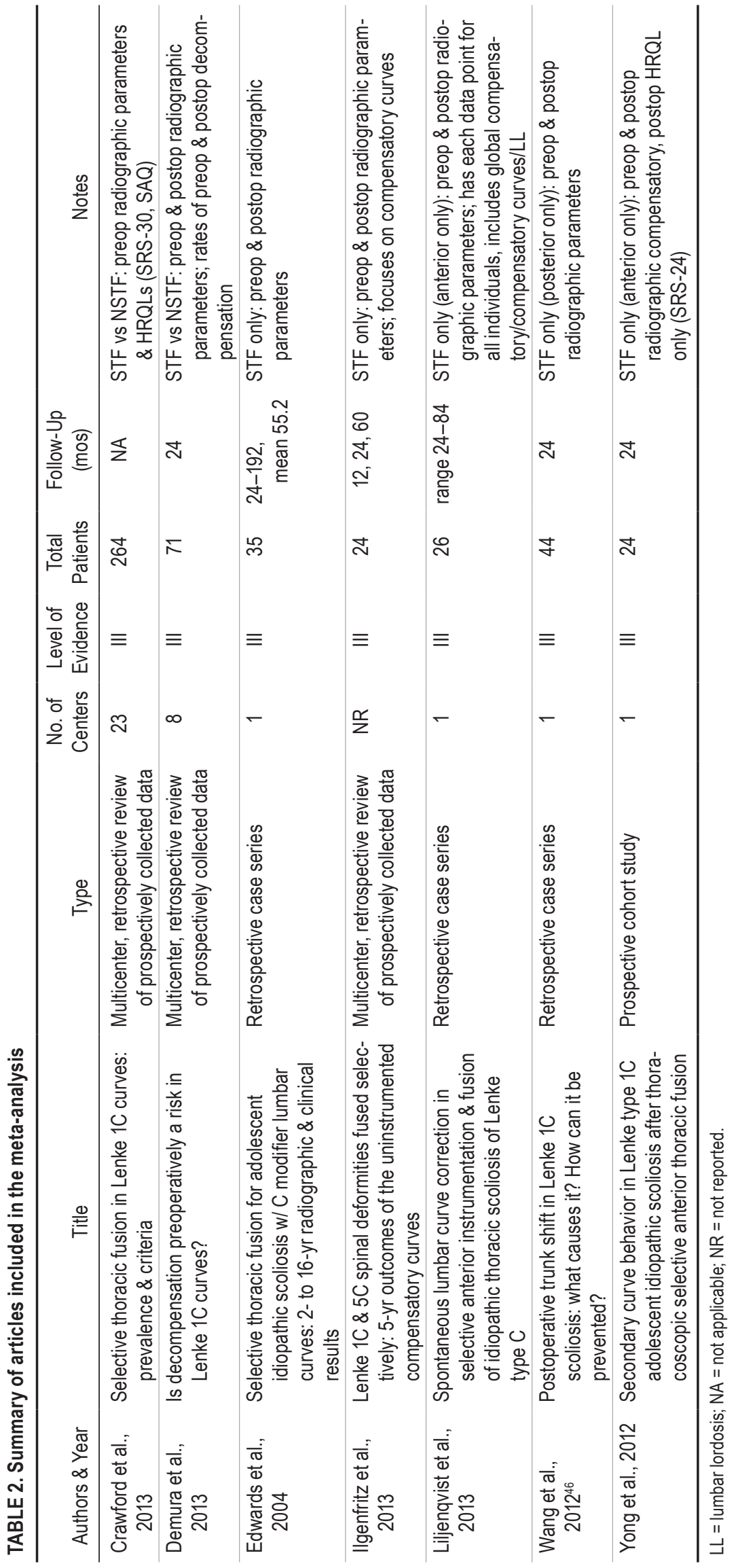


TABLE 3. Preoperative demographic data: STF versus NSTF*

\begin{tabular}{|c|c|c|c|}
\hline Variable & $\begin{array}{l}\text { STF Mean } \\
\text { (SD) }\end{array}$ & $\begin{array}{c}\text { NSTF Mean } \\
\text { (SD) }\end{array}$ & p Values \\
\hline No. of patients & 138 & 126 & \\
\hline Age in yrs & 14.7 & 14.8 & 0.377 \\
\hline Female (\%) & 89.8 & 86.4 & 0.379 \\
\hline \multicolumn{4}{|l|}{$S A Q$} \\
\hline Severity of deformity & $2.49(0.58)$ & $2.56(0.55)$ & 0.36 \\
\hline Unrelated to deformity & $3.47(1.18)$ & $3.88(1.04)$ & $0.010 \dagger$ \\
\hline Related to deformity & $1.97(1.02)$ & $1.83(0.94)$ & 0.286 \\
\hline \multicolumn{4}{|l|}{ SRS-22 } \\
\hline Total & $3.86(0.48)$ & $3.81(0.49)$ & 0.426 \\
\hline Pain & $4.13(0.77)$ & $3.92(0.79)$ & $0.038 \dagger$ \\
\hline Appearance & $3.31(0.62)$ & $3.32(0.63)$ & 0.933 \\
\hline Activity & $4.17(0.50)$ & $4.13(0.64)$ & 0.553 \\
\hline Mental & $3.93(0.73)$ & $3.92(0.69)$ & 0.874 \\
\hline Satisfaction & $3.61(0.97)$ & $3.69(0.90)$ & 0.519 \\
\hline
\end{tabular}

this surgical strategy. Although there is an abundance of literature regarding STF with respect to outcomes, the guidelines for use and reports of complications are less prevalent; studies are varied and heterogeneous in terms of surgical approaches, $23,33,35$ instrumentation, $23,27,35,41,43$ degree of correction,,$^{18,34,36,42-44}$ curve types, ${ }^{17,24,28,37,41,44}$ LIV, ${ }^{29,31,34,42}$ and radiographic parameters analyzed. Additionally, with more modern instrumentation and surgical correction techniques, many of the guidelines developed from the earlier literature may be outdated. By performing a meta-analysis using recent literature pertaining to the Lenke 1C subgroup, we have elucidated current treatment patterns and radiographic parameters that may serve as drivers for selecting STF versus NSTF.

When comparing pre- and postoperative radiographic parameters for STF, expected improvements are seen in the MT Cobb angle, TL/L Cobb angle, MT:TL/L Cobb angle ratios, coronal balance, and TL/L AVR, signifying overall improved balance and correction, with spontaneous lumbar compensatory curve correction. However, it is interesting to note that there are no significant changes in pre- and postoperative TL/L AVT in patients undergoing STF. This is probably secondary to only modest improvements in the lumbar curve position with STF. The cause of the relatively unchanged position of the lumbar curve in the STF can be possibly attributed to undercorrection of the thoracic curve to avoid coronal decompensation, resulting in only modest curve correction in the lumbar spine. The concept of avoiding overcorrection of the thoracic curve to prevent decompensation is an example of dogma that may not be applicable to modern instrumentation techniques.

Early positive experiences with Harrington rod instrumentation for STF are underscored with reports of postoperative coronal decompensation with the introduction of Cotrel-Dubousset instrumentation, which many studies attribute to thoracic overcorrection. ${ }^{2,6,31,43}$ Imrie et al. ${ }^{18}$
TABLE 4. Baseline comparison between characteristics within the STF group

\begin{tabular}{lccc}
\hline \multicolumn{1}{c}{ Authors \& Year } & Mean Age (yrs) & SD & No. \\
\hline Liljenqvist et al., 2013 & 15.2 & 2.3 & 26 \\
\hline Yong et al., 2012 & 14.8 & 2.1 & 24 \\
\hline Edwards et al., 2004 & 14.2 & 1.9 & 35 \\
\hline Ilgenfritz et al., 2013* & NR & NR & 24 \\
\hline Overall average & 14.7 & 2.1 & 85 \\
\hline * Only the Risser grade (a measure of skeletal maturity) & was reported in this
\end{tabular}

* Only the Risser grade (a measure of skeletal maturity) was reported in this study, which is why the article was not included in the paper.

report high correction rates with modern instrumentation without increased rates of decompensation in Lenke $1 \mathrm{C}$ curves. When patients with an MT curve correction greater than $80 \%$ are compared with patients with correction less than $40 \%$, the high correction group is able to achieve a lumbar correction that approaches what is seen on the lateral-bending film, resulting in a more balanced spine. The low correction group only obtains a spontaneous lumbar correction that is half of what is obtained on the lateral-bending film. Another study ${ }^{11}$ shows comparable clinical and radiographic results of posterior STF performed using hooks versus pedicle screws, and finds the pedicle-screw group allows for a higher degree of correction but with a lower incidence of postoperative coronal decompensation.

However, the literature still varies on whether the goal of STF should be to achieve a straighter spine or a more balanced one. Dobbs et al. ${ }^{12}$ showed excellent postoperative coronal balance with spontaneous lumbar curve correction in a cohort of 100 patients by using modern instrumentation techniques, with thoracic correction approximating what is achieved on preoperative thoracic push-prone radiographs. Additionally, it is notable that there is a significant increase in thoracic kyphosis and no change in lumbar lordosis in the pre- and postoperative comparisons of the STF group. Hence, patients undergoing STF did not encounter sagittal imbalance secondary to thoracic overcorrection, which is expected given the principle previously mentioned.

When comparing baseline preoperative radiographic parameters between the groups in the current study, patients chosen for NSTF have higher TL/L Cobb angles and TL/L AVT than patients who undergo STF. These data correlate with the results published by McCall and Bronson, ${ }^{28}$ who found that patients with lumbar curves greater than $45^{\circ}$ and with a low flexibility index are significantly more likely to develop postoperative progression of the uninstrumented lumbar curve with resultant spinal decompensation. Similarly, other studies suggest that larger, stiffer lumbar curves might be a contraindication for STF. ${ }^{25,28}$

The increased TL/L AVT seen in patients who ultimately receive an NSTF represents a greater degree of preoperative coronal translation. Dobbs et al. ${ }^{12}$ show that the presence of preoperative coronal translation places patients at significant risk of postoperative imbalance. In their cohort of patients with Lenke 1C curves, Demura et al. reported that those treated with STF had a 57\% incidence of 2-year 


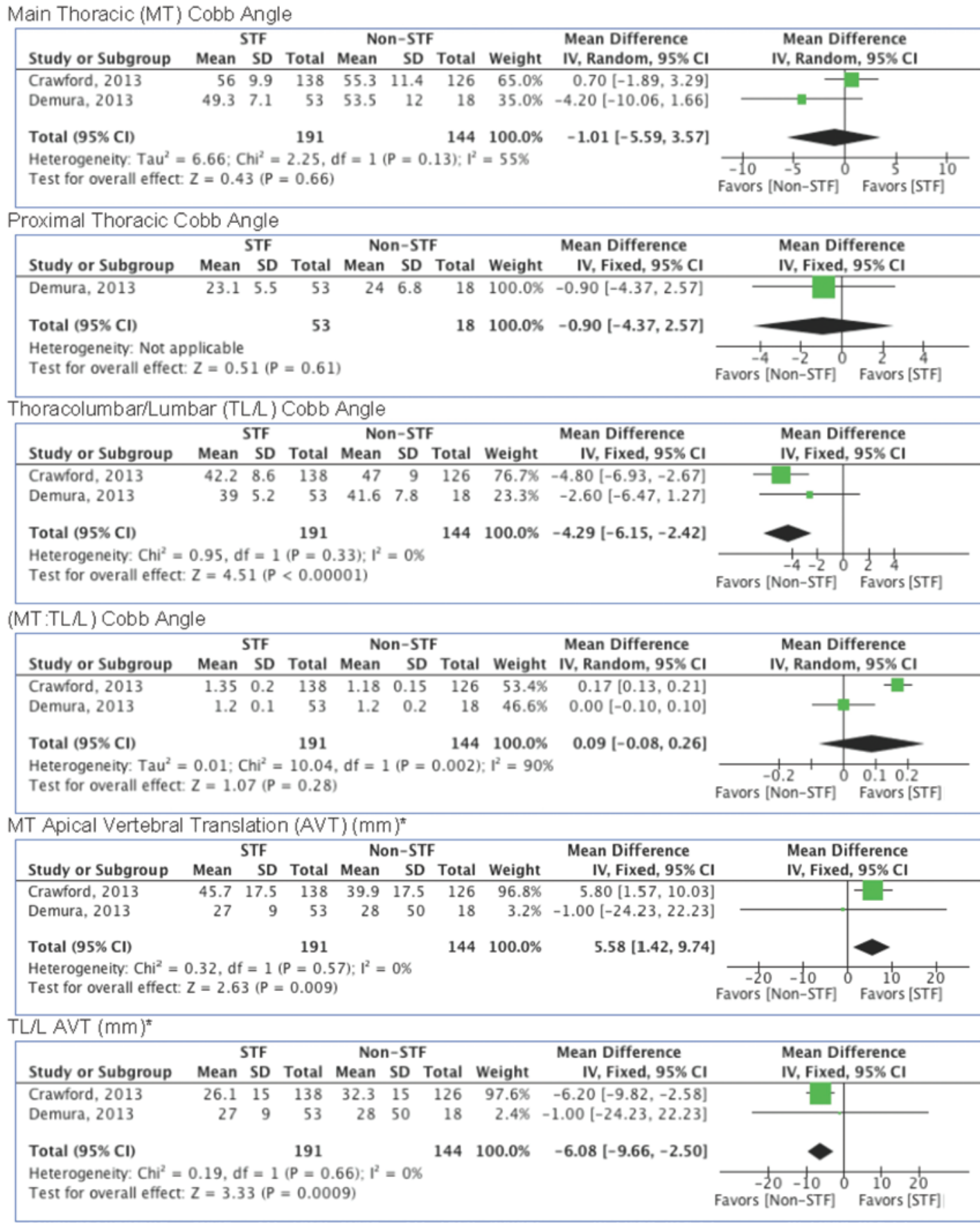

FIG. 2. Preoperative radiographic comparison between STF and NSTF. Asterisk denotes standard deviation used in Crawford et al., 2013, estimated from p value presented by Demura et al., 2013. IV = inverse variance. Figure is available in color online only.

decompensation if they are decompensated preoperatively (C-7 to central sacral vertical line $>2 \mathrm{~cm}$ ), versus a $31 \%$ decompensation rate if they are balanced preoperatively. Whether this amount of coronal translation is clinically significant and merits a role in the decision-making process remains to be seen.

When comparing pre- and postoperative radiographic parameters for the NSTF group, significant correction is achieved with respect to both MT and TL/L Cobb angles, as is expected with a longer fusion. When compar- ing postoperative radiographic parameters between STF and NSTF, the overall correction is similar with respect to MT Cobb angles and MT:TL/L ratios. Given the trend seen in the literature,,${ }^{17,20}$ it is expected that the STF group has a correction of the TL/L curve that mirrors that of the MT curve. Unfortunately, due to the limited sample data available, additional radiographic parameters were not analyzed.

Surprisingly, larger magnitudes of the MT Cobb angle and the MT:TL/L Cobb angle ratios are not significantly 


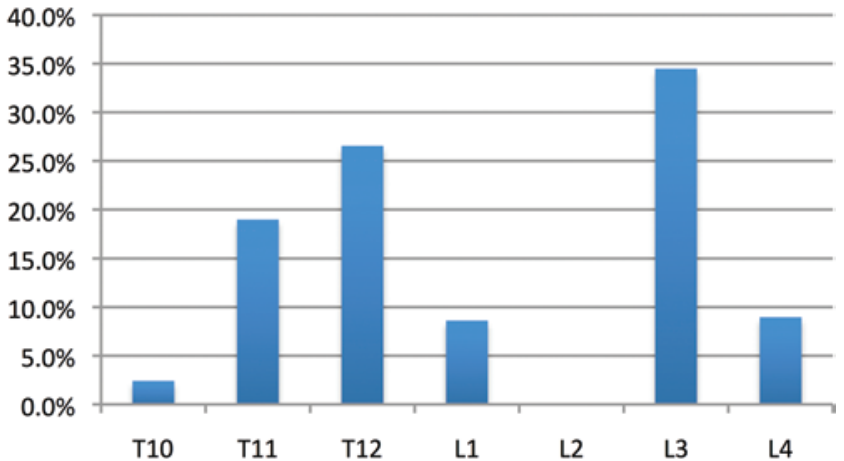

FIG. 3. Bar graph showing the LIV. Data were derived exclusively from two studies (Demura et al., 2013, and Liljenqvist et al., 2013). Figure is available in color online only.

associated with any specific treatment group. This is contrary to well-established guidelines recommended by Lenke et al., ${ }^{24}$ who recommend STF when the MT:TL/L and $\mathrm{AVT}$ values and the coronal translation ratios of the major curve intended for selective fusion to the minor compensatory curve are 1.2 or more. The reason for this deviation from traditional guidelines is unclear; perhaps surgeon choice may be more directly related to radiographic parameters as they relate to the lumbar compensatory curve. This finding may highlight the limitations of radiographic guidelines, because the clinical examination is an important component of determining the extent of instrumentation in patients undergoing spine surgery. Even if radiographic criteria are established in this patient population, the clinical examination, in conjunction with numerous other variables including patient preference and comorbidities, may alter decisions on treatment modalities.

Although HQRL scores were only collected in one study in our meta-analysis, it is important to note that patients who ultimately underwent STF have lower pain scores as well as less of a desire for appearance change, as measured by the SAQ: Unrelated to Deformity score. The SAQ is a modification of the Walter Reed Visual Assessment Scale and is used to assess the patient's perception of their spinal deformity. ${ }^{40}$ These trends may signify surgeon preference for NSTF in patients who may have a worse

TABLE 5. Change in pre- to postoperative radiographic values for the NSTF group*

\begin{tabular}{|c|c|c|c|}
\hline Variable & $\begin{array}{l}\text { Preop Mean } \\
\text { (SD) }\end{array}$ & $\begin{array}{l}\text { Postop Mean } \\
\text { (SD) }\end{array}$ & $p$ Value \\
\hline No. of patients & 18 & 18 & \\
\hline \multicolumn{4}{|l|}{ Cobb angle† } \\
\hline PT & $24(6.8)$ & $14.1(6.9)$ & $<0.01 \ddagger$ \\
\hline MT & $53.5(12.0)$ & $20.5(8.6)$ & $<0.01 \ddagger$ \\
\hline TL/L & $41.6(7.8)$ & $16.6(7.6)$ & $<0.01 \ddagger$ \\
\hline Cobb ratio; MT:TL/L & $1.2(0.2)$ & $1.5(1.0)$ & 0.21 \\
\hline
\end{tabular}

TABLE 6. Comparison of mean postoperative STF and NSTF values*

\begin{tabular}{|c|c|c|c|}
\hline Variable & $\begin{array}{l}\text { STF Mean } \\
\text { (SD) }\end{array}$ & $\begin{array}{l}\text { NSTF Mean } \\
\text { (SD) }\end{array}$ & $p$ Value \\
\hline No. of patients & 53 & 18 & \\
\hline \multicolumn{4}{|l|}{ Cobb angle $†$} \\
\hline PT & $13.1(6.1)$ & $14.1(6.9)$ & 0.58 \\
\hline MT & $22.3(6.8)$ & $20.5(8.6)$ & 0.42 \\
\hline TL/L & $23.1(5.5)$ & $16.6(7.6)$ & $<0.01 \ddagger$ \\
\hline Cobb ratio; MT:TL/L & $1.0(0.3)$ & $1.5(1.0)$ & 0.29 \\
\hline
\end{tabular}

overall perception of their spinal deformity. The ultimate goal of the surgeon and the patient can differ, and may not always necessarily correlate to radiographic parameters, as postulated by Newton et al. in their description of the deformity-flexibility quotient as a tool to guide patient satisfaction and surgeon preference. ${ }^{33}$ Larson et al. performed a retrospective cohort study comparing long-term clinical and radiographic outcomes for STF versus long fusion for AIS. ${ }^{22}$ Interestingly, their results suggest that the long-fusion patients are more pleased with the cosmetic results of having both curves fused, although there is no measurable difference between groups with respect to scoliometer measurements or SRS-24 domains related to postsurgical function and image.

This report is limited by the small number of studies that met inclusion criteria for meta-analysis. Furthermore, none of the studies that met inclusion criteria reported on results between surgical approaches, surgical technique, and instrumentation used. The current study's findings highlight the possibility that current treatment guidelines in this patient population may not be the main drivers of treatment. In light of the lack of universally accepted treatment guidelines for modern surgical techniques in this patient population, further research is needed to address this paucity of knowledge. Prospective, randomized studies or large database studies may be best suited to answer these questions.

\section{Conclusions}

Patients with larger lumbar compensatory curves with a larger degree of coronal translation as measured by the TL/L AVT are more likely to undergo an NSTF. Contrary to established guidelines, larger MT curve magnitudes and MT:TL/L Cobb angle ratios have not been found to influence the decision to pursue an STF. Although overall both STF and NSTF groups are found to display postoperative balance in the coronal plane, the STF group has only modest improvements in the lumbar curve position, as determined by a relatively unchanged TL/L AVT. Furthermore, surgeons may prefer NSTF in patients who may have a worse overall perception of their spinal deformity as measured by HRQL measures of pain and desire for appearance change. 


\begin{tabular}{|c|c|c|c|c|c|c|c|c|c|c|}
\hline \multirow[b]{2}{*}{ Study or Subgroup } & \multicolumn{3}{|c|}{ Post-op } & \multicolumn{3}{|c|}{ Pre-op } & \multirow[b]{2}{*}{ Weight } & Mean Difference & \multirow{2}{*}{\multicolumn{2}{|c|}{$\begin{array}{c}\text { Mean Difference } \\
\text { IV, Random, } 95 \% \mathrm{CI}\end{array}$}} \\
\hline & Mean & SD & Total & Mean & SD & Total & & IV, Random, $95 \% \mathrm{CI}$ & & \\
\hline Demura, 2013 & 22.3 & 6.8 & 53 & 49.3 & 7.1 & 53 & $24.6 \%$ & $-27.00[-29.65,-24.35]$ & $=$ & \\
\hline Edwards, 2004 & 38.1 & 10.2 & 35 & 60.2 & 9.7 & 35 & $17.3 \%$ & $-22.10[-26.76,-17.44]$ & - & \\
\hline Illgenfritz, 2013 & 21 & 7 & 24 & 49 & 9 & 24 & $17.6 \%$ & $-28.00[-32.56,-23.44]$ & - & \\
\hline Liljenqvist, 2013 & 29.2 & 4.8 & 26 & 62 & 8.9 & 26 & $19.9 \%$ & $-32.80[-36.69,-28.91]$ & - & \\
\hline Wang, 2012 & 21.8 & 67.8 & 44 & 54.4 & 40.7 & 44 & $1.5 \%$ & $-32.60[-55.97,-9.23]$ & & \\
\hline Yong, 2012 & 24.9 & 5.9 & 24 & 53 & 8.4 & 24 & $19.1 \%$ & $-28.10[-32.21,-23.99]$ & - & \\
\hline Total $(95 \% \mathrm{Cl})$ & & & 206 & & & 206 & $100.0 \%$ & $-27.78[-30.71,-24.85]$ & $\bullet$ & \\
\hline $\begin{array}{l}\text { Heterogeneity: Tau }{ }^{2}= \\
\text { Test for overall effect: }\end{array}$ & $\begin{array}{l}7.25: C \\
z=18\end{array}$ & $\begin{array}{l}C h i^{2}= \\
.61(P\end{array}$ & $\begin{array}{l}2.64 \\
<0.00\end{array}$ & $\begin{array}{l}\mathrm{df}=5 \\
001)\end{array}$ & $(P=0$. & .03); $1^{2}$ & $=60 \%$ & & $\begin{array}{l}-150 \quad-\frac{1}{25} \\
\text { Favors [pre] }\end{array}$ & $\begin{array}{cc}2 \frac{1}{25} & 50 \\
\text { Favors [post] }\end{array}$ \\
\hline
\end{tabular}

\begin{tabular}{|c|c|c|c|c|c|c|c|c|c|}
\hline \multicolumn{10}{|c|}{ Thoracolumbar Lumbar (TL $\Omega$ ) Cobb Angle } \\
\hline \multirow[b]{2}{*}{ Study or Subgroup } & \multicolumn{3}{|c|}{ Post-op } & \multicolumn{3}{|c|}{ Pre-op } & \multirow[b]{2}{*}{ Weight } & \multirow{3}{*}{$\begin{array}{c}\begin{array}{c}\text { Mean Difference } \\
\text { IV, Random, } 95 \% \mathrm{CI}\end{array} \\
-15.90[-17.92,-13.88]\end{array}$} & \multirow{2}{*}{$\begin{array}{c}\text { Mean Difference } \\
\text { IV, Random, } 95 \% \mathrm{Cl}\end{array}$} \\
\hline & Mean & SD & Total & Mean & SD & Total & & & \\
\hline Demura, 2013 & 23.1 & 5.5 & 55 & 39 & 5.2 & 53 & $36.8 \%$ & & $=$ \\
\hline |lgenfritz, 2013 & 28 & 9 & 24 & 40 & 6 & 24 & $13.4 \%$ & $-12.00[-16.33,-7.67]$ & . \\
\hline Liljenqvist, 2013 & 30.7 & 5.6 & 26 & 48 & 4.7 & 26 & $25.3 \%$ & $-17.30[-20.11,-14.49]$ & - \\
\hline Wang, 2012 & 24.2 & 22 & 44 & 41.7 & 9.5 & 44 & $5.7 \%$ & $-17.50[-24.58,-10.42]$ & \\
\hline Yong, 2012 & 25.4 & 6.6 & 24 & 43.5 & 5.6 & 24 & $18.9 \%$ & $-18.10[-21.56,-14.64]$ & $\rightarrow$ \\
\hline Total $(95 \% \mathrm{Cl})$ & & & 173 & & & 171 & $100.0 \%$ & $-16.24[-17.99,-14.48]$ & $\bullet$ \\
\hline \multicolumn{9}{|c|}{$\begin{array}{l}\text { Heterogeneity: Tau }=1.12 ; \mathrm{Ch}^{2}=5.57, \mathrm{df}=4(\mathrm{P}=0.23) ; \mathrm{I}^{2}=28 \% \\
\text { Test for overall effect: } \mathrm{Z}=18.13(\mathrm{P}<0.00001)\end{array}$} & 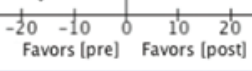 \\
\hline
\end{tabular}

\section{Ratio (MT:TL $\Omega$ ) Cobb Angle}

\begin{tabular}{|c|c|c|c|c|c|c|c|c|c|c|}
\hline \multirow[b]{2}{*}{ Study or Subgroup } & \multicolumn{3}{|c|}{ Post-op } & \multicolumn{3}{|c|}{ Pre-op } & \multicolumn{2}{|r|}{ Mean Difference } & \multirow{2}{*}{\multicolumn{2}{|c|}{$\begin{array}{l}\text { Mean Difference } \\
\text { IV, Fixed, } 95 \% \mathrm{Cl}\end{array}$}} \\
\hline & Mean & SD & Total & Mean & SD & Total & Weight & IV, Fixed, 95\% CI & & \\
\hline Demura, 2013 & 1 & 0.3 & 53 & 1.2 & 0.1 & 53 & $97.2 \%$ & $-0.20[-0.29,-0.11]$ & 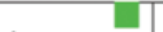 & \\
\hline Ilgenfritz, 2013 & 0.8 & 11.4 & 24 & 1.2 & 10.8 & 24 & $0.0 \%$ & $-0.40[-6.68,5.88]$ & & \\
\hline Wang. 2012 & 0.9 & 1.3 & 44 & 1.3 & 1.1 & 44 & $2.8 \%$ & $-0.40[-0.90,0.10]$ & & \\
\hline Total $(95 \% \mathrm{CI})$ & & & 121 & & & 121 & $100.0 \%$ & $-0.21[-0.29,-0.12]$ & $\bullet$ & \\
\hline \multicolumn{6}{|c|}{$\begin{array}{l}\text { Heterogeneity: Chi }{ }^{2}=0.59, \mathrm{df}=2(\mathrm{P}=0.74) ; \mathrm{I}^{2}=0 \% \\
\text { Test for overall effect: } \mathrm{Z}=4.80(\mathrm{P}<0.00001)\end{array}$} & & & & $\begin{array}{cc}-1 & -0.5 \\
& \text { Favors [pre] }\end{array}$ & $\begin{array}{c}1 \\
0.5 \\
\text { Favors [post] }\end{array}$ \\
\hline
\end{tabular}

\begin{tabular}{|c|c|c|c|c|c|c|c|c|c|}
\hline \multirow[b]{2}{*}{ Study or Subgroup } & \multicolumn{3}{|c|}{ Post-op } & \multicolumn{3}{|c|}{ Pre-op } & \multicolumn{2}{|r|}{ Mean Difference } & \multirow{2}{*}{$\begin{array}{l}\text { Mean Difference } \\
\text { IV, Fixed, } 95 \% \mathrm{CI}\end{array}$} \\
\hline & Mean & SD & Total & Mean & SD & Total & Weight & IV, Fixed, $95 \% \mathrm{CI}$ & \\
\hline Edwards, 2004 & 26.2 & 9.6 & 35 & 28.8 & 6.4 & 35 & $39.1 \%$ & $-2.60[-6.42,1.22]$ & -7 \\
\hline Liljenqvist, 2013 & 29 & 8 & 26 & 28 & 0.5 & 26 & $60.2 \%$ & $1.00[-2.08,4.08]$ & \\
\hline Wang, 2012 & 22.9 & 81.4 & 44 & 24.1 & 64.1 & 44 & $0.6 \%$ & $-1.20[-31.81,29.41]$ & \\
\hline Total $(95 \% \mathrm{Cl})$ & & & 105 & & & 105 & $100.0 \%$ & $-0.42[-2.81,1.97]$ & \\
\hline \multicolumn{6}{|c|}{$\begin{array}{l}\text { Heterogeneity: } \mathrm{Ch}^{2}=2.07, \mathrm{df}=2(\mathrm{P}=0.36): \mathrm{I}^{2}=3 \% \\
\text { Test for overall effect: } Z=0.35(P=0.73)\end{array}$} & & & & 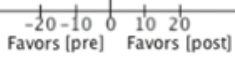 \\
\hline
\end{tabular}

\begin{tabular}{|c|c|c|c|c|c|c|c|c|c|c|}
\hline \multicolumn{11}{|c|}{ Coronal Balance (cm) } \\
\hline \multirow[b]{2}{*}{ Study or Subgroup } & \multicolumn{3}{|c|}{ Post-op } & \multicolumn{3}{|c|}{ Pre-op } & \multirow[b]{2}{*}{ Weight } & \multirow{2}{*}{$\begin{array}{l}\text { Mean Difference } \\
\text { IV, Fixed, } 95 \% \mathrm{CI}\end{array}$} & \multirow{2}{*}{\multicolumn{2}{|c|}{$\begin{array}{l}\text { Mean Difference } \\
\text { IV, Fixed, } 95 \% \mathrm{CI}\end{array}$}} \\
\hline & Mean & SD & Total & Mean & SD & Total & & & & \\
\hline Edwards, 2004 & -1.8 & 1.4 & 35 & -2.4 & 1.4 & 35 & $37.3 \%$ & $0.60[-0.06,1.26]$ & & $\square-$ \\
\hline Ilgenfritz, 2013 & -1.7 & 1 & 24 & -1.9 & 1.9 & 24 & $21.7 \%$ & $0.20[-0.66,1.06]$ & & \\
\hline Liljenqvist, 2013 & -1.4 & 1.2 & 26 & -1.9 & 1.1 & 26 & $41.0 \%$ & $0.50[-0.13,1.13]$ & & $-=$ \\
\hline Total $(95 \% \mathrm{CI})$ & & & 85 & & & 85 & $100.0 \%$ & $0.47[0.07,0.87]$ & & \\
\hline \multirow{2}{*}{\multicolumn{6}{|c|}{$\begin{array}{l}\text { Heterogeneity: } \mathrm{Ch}^{2}=0.54, \mathrm{df}=2(\mathrm{P}=0.76) ; \mathrm{I}^{2}=0 \% \\
\text { Test for overall effect: } \mathrm{Z}=2.31(\mathrm{P}=0.02)\end{array}$}} & & & & -2 & $\frac{1}{2}$ \\
\hline & & & & & & & & & Favors [pre] & Favors [post] I \\
\hline
\end{tabular}

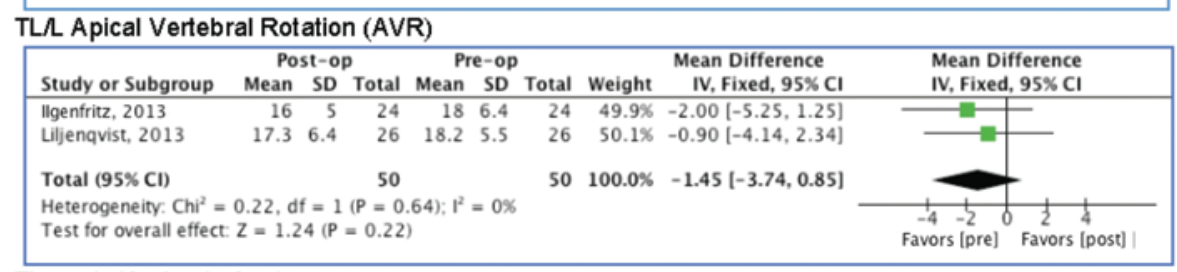

\begin{tabular}{|c|c|c|c|c|c|c|c|c|c|c|}
\hline \multicolumn{11}{|c|}{ Thoracic Kyphosis Angle } \\
\hline \multirow[b]{2}{*}{ Study or Subgroup } & \multicolumn{3}{|c|}{ Post-op } & \multicolumn{3}{|c|}{ Pre-op } & \multirow[b]{2}{*}{ Weight } & \multirow{2}{*}{$\begin{array}{l}\text { Mean Difference } \\
\text { IV, Random, } 95 \% \mathrm{CI}\end{array}$} & \multirow{2}{*}{\multicolumn{2}{|c|}{$\begin{array}{c}\text { Mean Difference } \\
\text { IV, Random, } 95 \% \mathrm{CI}\end{array}$}} \\
\hline & Mean & SD & Total & Mean & SD & Total & & & & \\
\hline Ilgenfritz, 2013 & 25 & 7 & 24 & 18 & 6 & 24 & $35.1 \%$ & $7.00[3.31,10.69]$ & & $\rightarrow-$ \\
\hline Liljenqvist, 2013 & 32.8 & 8 & 26 & 29.2 & 12.2 & 26 & $26.9 \%$ & $3.60[-2.01,9.21]$ & & \\
\hline Yong, 2012 & 29.3 & 5.1 & 24 & 17.6 & 5.6 & 24 & $38.0 \%$ & $11.70[8.67,14.73]$ & & $\rightarrow$ \\
\hline \multirow{2}{*}{\multicolumn{8}{|c|}{$\begin{array}{l}\text { Heterogeneity: } \text { Tau }^{2}=11.57 ; \mathrm{Chi}^{2}=7.73, \mathrm{df}=2(\mathrm{P}=0.02) ; \mathrm{I}^{2}=74 \% \\
\text { Test for overall effect: } Z=3.42(\mathrm{P}=0.0006)\end{array}$}} & $7.87[3.36,12.39]$ & & \\
\hline & & & & & & & & & $\begin{array}{c}-10-\frac{1}{0} \\
\text { Favors [pre] }\end{array}$ & $\begin{array}{cc}510 \\
\text { Favors [post] }\end{array}$ \\
\hline
\end{tabular}

\begin{tabular}{|c|c|c|c|c|c|c|c|c|c|}
\hline \multicolumn{10}{|l|}{ Lumbar Lordosis } \\
\hline \multirow[b]{2}{*}{ Study or Subgroup } & \multicolumn{3}{|c|}{ Post-op } & \multicolumn{3}{|c|}{ Pre-op } & \multicolumn{2}{|r|}{ Mean Difference } & \multirow{2}{*}{$\begin{array}{l}\text { Mean Difference } \\
\text { IV, Fixed, } 95 \% \mathrm{CI}\end{array}$} \\
\hline & Mean & SD & Total & Mean & SD & Total & Weight & IV, Fixed, 95\% CI & \\
\hline Ilgenfritz, 2013 & 60 & 11 & 24 & 59 & 11 & 24 & $44.7 \%$ & $1.00[-5.22,7.22]$ & $\longrightarrow$ \\
\hline Liljenqvist, 2013 & $\$ 1.1$ & 10.2 & 26 & 54.5 & 10.4 & 26 & $55.3 \%$ & $-3.40[-9.00,2.20]$ & \\
\hline \multirow{2}{*}{\multicolumn{6}{|c|}{$\begin{array}{l}\text { Total }(95 \% \mathrm{Cl}) \quad 50 \\
\text { Heterogeneity: Chi }{ }^{2}=1.06, \mathrm{df}=1(\mathrm{P}=0.30) ; \mathrm{I}^{2}=6 \% \\
\text { Test for overall effect: } Z=0.67(P=0.50)\end{array}$}} & so & $100.0 \%$ & $-1.43[-5.59,2.73]$ & \\
\hline & & & & & & & & & $\begin{array}{ccccc}-10 & -5 & 0 & 5 & 10 \\
\text { Favors [pre] } & \text { Favors [post] }\end{array}$ \\
\hline
\end{tabular}

FIG. 4. Comparison between pre- and postoperative values for STF radiographic parameters. Figure is available in color online only. 


\section{References}

1. Arlet V, Marchesi D, Papin P, Aebi M: Decompensation following scoliosis surgery: treatment by decreasing the correction of the main thoracic curve or "letting the spine go." Eur Spine J 9:156-160, 2000

2. Benli IT, Tüzüner M, Akalin S, Kiş M, Aydin E, Tandoğan $\mathrm{R}$ : Spinal imbalance and decompensation problems in patients treated with Cotrel-Dubousset instrumentation. Eur Spine J 5:380-386, 1996

3. Bridwell KH, McAllister JW, Betz RR, Huss G, Clancy M, Schoenecker PL: Coronal decompensation produced by Cotrel-Dubousset "derotation" maneuver for idiopathic right thoracic scoliosis. Spine (Phila Pa 1976) 16:769-777, 1991

4. Burton DC, Asher MA, Lai SM: The selection of fusion levels using torsional correction techniques in the surgical treatment of idiopathic scoliosis. Spine (Phila Pa 1976) 24:1728-1739, 1999

5. Chang KW, Chang KI, Wu CM: Enhanced capacity for spontaneous correction of lumbar curve in the treatment of major thoracic-compensatory $\mathrm{C}$ modifier lumbar curve pattern in idiopathic scoliosis. Spine (Phila Pa 1976) 32:3020-3029, 2007

6. Chang MS, Bridwell KH, Lenke LG, Cho W, Baldus C, Auerbach JD, et al: Predicting the outcome of selective thoracic fusion in false double major lumbar " $C$ " cases with five- to twenty-four-year follow-up. Spine (Phila Pa 1976) 35:21282133, 2010

7. Connolly PJ, Von Schroeder HP, Johnson GE, Kostuik JP: Adolescent idiopathic scoliosis. Long-term effect of instrumentation extending to the lumbar spine. J Bone Joint Surg Am 77:1210-1216, 1995

8. Crawford CH III, Bridwell KH, Cho W, Buchowski JM, O'Shaughnessy BA, Chang MS, et al: Extension of prior idiopathic scoliosis fusions to the sacrum: a matched cohort analysis of sixty patients with minimum two-year follow-up. Spine (Phila Pa 1976) 35:1843-1848, 2010

9. Crawford CH III, Lenke LG, Sucato DJ, Richards BS III, Emans JB, Vitale MG, et al: Selective thoracic fusion in Lenke 1C curves: prevalence and criteria. Spine (Phila Pa 1976) 38:1380-1385, 2013

10. Demura S, Yaszay B, Bastrom TP, Carreau J, Newton PO: Is decompensation preoperatively a risk in Lenke $1 \mathrm{C}$ curves? Spine (Phila Pa 1976) 38:E649-E655, 2013

11. Dobbs MB, Lenke LG, Kim YJ, Kamath G, Peelle MW, Bridwell KH: Selective posterior thoracic fusions for adolescent idiopathic scoliosis: comparison of hooks versus pedicle screws. Spine (Phila Pa 1976) 31:2400-2404, 2006

12. Dobbs MB, Lenke LG, Walton T, Peelle M, Della Rocca G, Steger-May K, et al: Can we predict the ultimate lumbar curve in adolescent idiopathic scoliosis patients undergoing a selective fusion with undercorrection of the thoracic curve? Spine (Phila Pa 1976) 29:277-285, 2004

13. Edwards CL, Lenke LG, Peelle M, Sides B, Rinella A, Bridwell KH: Selective thoracic fusion for adolescent idiopathic scoliosis with c modifier lumbar curves : 2- to 16-year radiographic and clinical results. Spine (Phila Pa 1976) 29:536-546, 2004

14. Frez R, Cheng JC, Wong EM: Longitudinal changes in trunkal balance after selective fusion of King II curves in adolescent idiopathic scoliosis. Spine (Phila Pa 1976) 25:1352-1359, 2000

15. Higgins JPT, Green S (eds): Section 7.7.7.2 Obtaining standard errors from confidence intervals and $\mathrm{P}$ values: absolute (difference) measures. Cochrane Handbook for Systematic Reviews of Interventions. (http://handbook.cochrane.org) [Accessed May 13, 2015]

16. Hosman AJ, Slot GH, van Limbeek J, Beijneveld WJ: Rip hump correction and rotation of the lumbar spine after selective thoracic fusion. Eur Spine J 5:394-399, 1996
17. Ilgenfritz RM, Yaszay B, Bastrom TP, Newton PO: Lenke $1 \mathrm{C}$ and 5C spinal deformities fused selectively: 5-year outcomes of the uninstrumented compensatory curves. Spine (Phila Pa 1976) 38:650-658, 2013

18. Imrie M, Yaszay B, Bastrom TP, Wenger DR, Newton PO: Adolescent idiopathic scoliosis: should 100\% correction be the goal? J Pediatr Orthop 31 (1 Suppl):S9-S13, 2011

19. Jansen RC, van Rhijn LW, Duinkerke E, van Ooij A: Predictability of the spontaneous lumbar curve correction after selective thoracic fusion in idiopathic scoliosis. Eur Spine J 16:1335-1342, 2007

20. Kalen V, Conklin M: The behavior of the unfused lumbar curve following selective thoracic fusion for idiopathic scoliosis. Spine (Phila Pa 1976) 15:271-274, 1990

21. King HA, Moe JH, Bradford DS, Winter RB: The selection of fusion levels in thoracic idiopathic scoliosis. J Bone Joint Surg Am 65:1302-1313, 1983

22. Larson AN, Fletcher ND, Daniel C, Richards BS: Lumbar curve is stable after selective thoracic fusion for adolescent idiopathic scoliosis: a 20-year follow-up. Spine (Phila Pa 1976) 37:833-839, 2012

23. Lenke LG, Betz RR, Bridwell KH, Harms J, Clements DH, Lowe TG: Spontaneous lumbar curve coronal correction after selective anterior or posterior thoracic fusion in adolescent idiopathic scoliosis. Spine (Phila Pa 1976) 24:16631672, 1999

24. Lenke LG, Bridwell KH, Baldus C, Blanke K: Preventing decompensation in King type II curves treated with CotrelDubousset instrumentation. Strict guidelines for selective thoracic fusion. Spine (Phila Pa 1976) 17 (8 Suppl):S274S281, 1992

25. Lenke LG, Edwards CC II, Bridwell KH: The Lenke classification of adolescent idiopathic scoliosis: how it organizes curve patterns as a template to perform selective fusions of the spine. Spine (Phila Pa 1976) 28:S199-S207, 2003

26. Liljenqvist U, Halm H, Bullmann V: Spontaneous lumbar curve correction in selective anterior instrumentation and fusion of idiopathic thoracic scoliosis of Lenke type C. Eur Spine J 22 Suppl 2:S138-S148, 2013

27. Liljenqvist U, Lerner T, Bullmann V: [Selective fusion of idiopathic scoliosis with respect to the Lenke classification.] Orthopade 38:189-192, 194-197, 2009 (Ger)

28. McCall RE, Bronson W: Criteria for selective fusion in idiopathic scoliosis using Cotrel-Dubousset instrumentation. J Pediatr Orthop 12:475-479, 1992

29. McCance SE, Denis F, Lonstein JE, Winter RB: Coronal and sagittal balance in surgically treated adolescent idiopathic scoliosis with the King II curve pattern. A review of 67 consecutive cases having selective thoracic arthrodesis. Spine (Phila Pa 1976) 23:2063-2073, 1998

30. Moe JH: A critical analysis of methods of fusion for scoliosis: an evaluation in two hundred and sixty-six patients. 1958. Clin Orthop Relat Res 460:21-28, 2007

31. Moore MR, Baynham GC, Brown CW, Donaldson DH, Odom JA Jr: Analysis of factors related to truncal decompensation following Cotrel-Dubousset instrumentation. J Spinal Disord 4:188-192, 1991

32. Newton PO, Faro FD, Lenke LG, Betz RR, Clements DH, Lowe TG, et al: Factors involved in the decision to perform a selective versus nonselective fusion of Lenke 1B and 1C (King-Moe II) curves in adolescent idiopathic scoliosis. Spine (Phila Pa 1976) 28:S217-S223, 2003

33. Newton PO, Upasani VV, Bastrom TP, Marks MC: The deformity-flexibility quotient predicts both patient satisfaction and surgeon preference in the treatment of Lenke 1B or 1C curves for adolescent idiopathic scoliosis. Spine (Phila Pa 1976) 34:1032-1039, 2009

34. Patel PN, Upasani VV, Bastrom TP, Marks MC, Pawelek JB, Betz RR, et al: Spontaneous lumbar curve correction in se- 
lective thoracic fusions of idiopathic scoliosis: a comparison of anterior and posterior approaches. Spine (Phila Pa 1976) 33:1068-1073, 2008

35. Potter BK, Kuklo TR, Lenke LG: Radiographic outcomes of anterior spinal fusion versus posterior spinal fusion with thoracic pedicle screws for treatment of Lenke Type I adolescent idiopathic scoliosis curves. Spine (Phila Pa 1976) 30:1859-1866, 2005

36. Puno RM, An KC, Puno RL, Jacob A, Chung SS: Treatment recommendations for idiopathic scoliosis: an assessment of the Lenke classification. Spine (Phila Pa 1976) 28:21022115, 2003

37. Richards BS: Lenke 1C, King type II curves: surgical recommendations. Orthop Clin North Am 38:511-520, vi, 2007

38. Richards BS: Lumbar curve response in type II idiopathic scoliosis after posterior instrumentation of the thoracic curve. Spine (Phila Pa 1976) 17 (8 Suppl):S282-S286, 1992

39. Ritzman TF, Upasani VV, Bastrom TP, Betz RR, Lonner BS, Newton PO: Comparison of compensatory curve spontaneous derotation after selective thoracic or lumbar fusions in adolescent idiopathic scoliosis. Spine (Phila Pa 1976) 33:2643-2647, 2008

40. Sanders JO, Harrast JJ, Kuklo TR, Polly DW, Bridwell KH, Diab M, et al: The Spinal Appearance Questionnaire: results of reliability, validity, and responsiveness testing in patients with idiopathic scoliosis. Spine (Phila Pa 1976) 32:27192722, 2007

41. Suk SI, Lee SM, Chung ER, Kim JH, Kim WJ, Sohn HM: Determination of distal fusion level with segmental pedicle screw fixation in single thoracic idiopathic scoliosis. Spine (Phila Pa 1976) 28:484-491, 2003

42. Takahashi J, Newton PO, Bastrom TP: Selective thoracic fusion in adolescent idiopathic scoliosis: factors influencing the selection of the optimal lowest instrumented vertebra. Spine (Phila Pa 1976) 36:1131-1141, 2011

43. Thompson JP, Transfeldt EE, Bradford DS, Ogilvie JW, Boachie-Adjei O: Decompensation after Cotrel-Dubousset instrumentation of idiopathic scoliosis. Spine (Phila Pa 1976) 15:927-931, 1990

44. Trobisch PD, Samdani AF, Pahys JM, Cahill PJ: Postoperative trunk shift in Lenke 1 and 2 curves: how common is it? and analysis of risk factors. Eur Spine J 20:1137-1140, 2011

45. Von Lackum WH, Miller JP: Critical observations of the results in the operative treatment of scoliosis. J Bone Joint Surg Am 31A:102-106, 1949
46. Wang Y, Bünger CE, Wu C, Zhang Y, Hansen ES: Postoperative trunk shift in Lenke 1C scoliosis: what causes it? How can it be prevented? Spine (Phila Pa 1976) 37:1676-1682, 2012

47. Wang Y, Bünger CE, Zhang Y, Wu C, Hansen ES: Postoperative spinal alignment remodeling in Lenke $1 \mathrm{C}$ scoliosis treated with selective thoracic fusion. Spine J 12:73-80, 2012

48. Yong MRNO, Izatt MT, Adam CJ, Labrom RD, Askin GN: Secondary curve behavior in Lenke type $1 \mathrm{C}$ adolescent idiopathic scoliosis after thoracoscopic selective anterior thoracic fusion. Spine (Phila Pa 1976) 37:1965-1974, 2012

\section{Disclosure}

The authors report no conflict of interest concerning the materials or methods used in this study or the findings specified in this paper.

\section{Author Contributions}

Conception and design: all authors. Acquisition of data: all authors. Analysis and interpretation of data: all authors. Drafting the article: all authors. Critically revising the article: all authors. Reviewed submitted version of manuscript: all authors. Approved the final version of the manuscript on behalf of all authors: Passias. Statistical analysis: all authors. Administrative/technical/ material support: all authors. Study supervision: Passias.

\section{Supplemental Information Previous Presentation}

This manuscript has previously been presented in abstract form as an electronic poster (Boniello A, Yang S, Hasan S, et al.: "Selective versus non-selective thoracic fusion in Lenke 1C curves: a meta-analysis of baseline characteristics and postoperative outcomes.") at the 49th Annual Spine Research Society Meeting and Course, September 10-13, 2014, in Anchorage, Alaska.

\section{Correspondence}

Peter G. Passias, New York Spine Institute, 361 Merrick Ave., Westbury, New York 11590. email: pgpassias@yahoo.com. 